\title{
Malignancy in patients with systemic sclerosis: a reply to the article by Siau et al.
}

\author{
Marc Wooten
}

Received: 15 January 2010 / Accepted: 14 February 2010 / Published online: 11 March 2010

(C) US Government 2010

Dear Dr. Lemmel:

I have read with interest the article by Keith Siau and colleagues entitled, "Malignancy in scleroderma patients from south west England: a population-based cohort study" (Rheumatology Int 2010; doi 10.1007/s00296-009-1348-y). The authors point out the rarity of these two disorders coexisting.

The authors mention that there is an increase in risk in patients for breast cancer and hematological malignancies. My extensive review of the literature indicated that there was an overall increased risk of lung and breast cancer, but not an increased risk for hematological malignancies (Wooten MD, Systemic Sclerosis and Malignancy: A Review of the Literature, Southern Medical Journal 101:59-62, 2008). This was true in patients with both limited and diffuse systemic sclerosis, and no correlation could be clearly established with autoantibodies.

While the coexistence of these two disorders still remains a relatively rare phenomenon, malignancy should be considered in patients who manifest signs and symptoms of both disorders. 